INDONESIAN HEALTH ISSUE

\title{
PENGARUH PENGETAHUAN TENTANG DYSMENORHEA TERHADAP AKTIVITAS BELAJAR DI SMAN 3 NABIRE
}

\author{
Anisa Nanang Sulistiyowati ${ }^{1}$, Christina Tien Popang ${ }^{2}$ \\ ${ }^{1,2}$ Prodi D III Kebidanan Nabire Poltekkes Kemenkes Jayapura \\ Email korespondensi: anisananangs1@gmail.com \\ No HP: 081354119246
}

\section{ARTICLE INFO \\ Received: \\ 12 Januari 2022 \\ Accepted: \\ 14 Februari 2022 \\ Published: \\ 16 Februari 2022}

\section{Kata Kunci:}

Dysmenorhoe;

Aktivitas belajar

\section{Keywords:}

Dysmenorhoe;

Learning activity

\begin{abstract}
ABSTRAK
Latar Belakang: Dysmenore merupakan salah satu masalah ginekologi yang paling umum dialami wanita dari berbagai tingkat usia. Angka kejadian dismenore di dunia sangat besar. Rata-rata lebih dari $50 \%$ perempuan di setiap dunia mengalaminya. Tujuan: untuk mengetahui apakah ada pengaruh tingkat pengetahuan tentang dysmenorhea terhadap aktivitas belajar siswa di SMAN 3 Nabire Kabupaten Nabire. Metode: survey analitik dengan pendekatan waktu cross sectional. Populasi dalam penelitian ini berjumlah 273 orang. Metode pengambilan sampel menggunakan purposive sampling dan didapatkan sampel sebanyak 121 responden. Analisa data menggunakan uji Kendall-tau. Hasil: ada hubungan yang signifikan (nyata) antara variabel Pengetahuan Siswi tentang disminore dengan aktifitas belajar $p$ value $0,042(<0,05)$, koefisien korelasi $-0,183$. Kesimpulan: makin tinggi pengetahuan siswi tentang disminore maka semakin rendah jumlah siswa yang mengalami gangguang aktivitas belajar.
\end{abstract}

\begin{abstract}
Background: Dysmenorrhea was one of the most common gynecological problems experienced by women of different ages. The number of dysmenorrhea events in the world is huge. On average, more than $50 \%$ of women in the world experience it. Objective: to find out if there is an influence of the level of knowledge about dysmenorhea on the learning activities of students in SMAN 3 Nabire Nabire Regency. Method: analytical survey with a cross sectional time approach. The population in this study was 273 people. Sampling method using purposive sampling and obtained a sample of 121 respondents. Data analysis using the Kendall-tau test. Results: there is a significant (noticeable) relationship between the student knowledge variable on dysminore and learning activity $p$ value $0.042(<0.05)$, correlation coefficient -0.183. Conclusion: The higher the student's knowledge of dysminore, the lower the number of students who experience impaired learning activities.
\end{abstract}




\section{PENDAHULUAN}

Pada setiap bulannya wanita selalu mengalami menstruasi. Menstruasi terjadi akibat adanya interaksi hormon di dalam tubuh manusia. Menurut Anurogo (2011) interaksi hormon yang dikeluarkan oleh hipotalamus, dan indung telur menyebabkan lapisan sel rahim mulai berkembang dan menebal. Hormonhormon tersebut kemudian akan mememberikan sinyal pada telur di dalam indung telur untuk berkembang. Telur akan dilepaskan dari indung telur menuju tuba falopi dan menuju uterus. Telur yang tidak dibuahi oleh sperma akan menyebabkan terjadinya peluruhan pada endometrium, luruhnya endometrium menyebabkan perdarahan pada vagina yang disebut dengan menstruasi.

Setiap wanita normal akan mengalami menstruasi setiap bulannya. Beberapa wanita merasakan rasa nyeri pada tiap siklus menstruasi. Istilah dismenore (dysmenorrhea) berasal dari kata dalam bahasa yunani kuno. Kata tersebut berasal dari dys yang berarti sulit, nyeri, abnormal, Meno berarti bulan; dan rrhea yang berarti aliran atau arus. Secara singkat dismenore dapat di definisikan sebagai aliran menstruasi yang sulit atau menstruasi yang mengalami nyeri (Anurogo, 2011).

Dysmenorhoe adalah nyeri haid menjelang atau selama haid, sampai wanita tersebut tidak dapat bekerja dan harus tidur. Nyeri bersamaan dengan rasa mual, sakit kepala, perasaan mau pingsan, lekas marah (Mansjoer, 2003).

Dismenore yang dialami setiap siklus menstruasi merupakan pertanda adanya gangguan di dalam tubuh seseorang. Sari, Indrawati, \& Harjanto (2012) mengatakan bahwa dismenore dapat berasal dari kram rahim saat proses menstruasi, dismenore dapat timbul akibat gangguan pada organ reproduksi, faktor hormonal maupun faktor psikologis dan dapat menimbulkan tergganggunya aktivitas sehari-hari.

Masa remaja adalah suatu tahap antara masa kanak-kanak dengan masa dewasa. Dalam masa ini, remaja berkembang kearah kematangan seksual, memantapkan identitas sebagai individu yang terpisah dari keluarga, dan menghadapi tugas menentukan cara mencari mata pencaharian (Atkinson, 2005). Batasan usia remaja adalah 10-19 tahun. Jumlah kelompok usia 10-19 tahun di Indonesia menurut Sensus Penduduk 2010 sebanyak 43,5 juta atau sekitar $18 \%$ dari jumlah penduduk. Di dunia diperkirakan kelompok remaja berjumlah 1,2 milyar atau $18 \%$ dari jumlah penduduk dunia (WHO, 2014). Pada masa ini remaja pasti akan mengalami suatu keadaan yang dinamakan menstruasi. Dimana hal tersebut merupakan suatu fase yang menandakan sudah meninggalkan masa kanak-kanak menuju masa remaja dan ini merupakan suatu perkembangan yang dinamis (Kumalasari, 2012).

Masa remaja dikenal sebagai masa yang penuh kesukaran. Bukan saja kesukaran bagi individual, tetapi juga bagi orang tua dan masyarakat. Hal ini disebabkanmasa remaja merupakan masa transisi antara kanak-kanak dan dewasa. Masa transisi ini sering kali menghadapi individu yang bersangkutan kepada situasi yang membingungkan, disatu pihak ia masih kanak-kanak, tapi dilain pihak ia harus bertingkah laku seperti orang dewasa (Purwanto, 2003).

Kejadian dismenore paling banyak terjadi pada wanita produktif sebanyak 45-95\%, dalam penelitian di Hongkong sebanyak $80 \%$ remaja yang mengalami dismenore, $75 \%$ mengalami masalah kekurangan kemampuan konsentrasi terhadap pelajaran (Ngu dkk, 2013). 
Penderita dismenore paling banyak terjadi pada masa remaja atau masa produktif, akibatnya dismenore menyebabkan ketidakhadiran pada absensi sekolah sebanyak 39,9\% (Handayani, 2013). Ditambahkan dalam (Gulzar, dkk,2015) 40\% wanita di Pakistan tidak masuk sekolah dan menambah absen selama mereka dismenore, dan di Iran sebanyak 51\% wanita absen dari pekerjaan atau sekolah karena mengalami dismenore.

Dalam jurnal Occupational Environtmentaldi Indonesia sendiri prevalensi angka kejadian dismenore cukup tinggi yaitu 54,98 \% dimenore primer dan 9,36\% dismenore sekunder (Murtiningsih, 2015). Menurut (Fatmawati,2016) di Jawa Tengah angka kejadian dismenore secara umum sebanyak $56 \%$. Prevalensi dismenore yang terjadi pada remaja di kota Surakarta sebanyak $87,7 \%$, dan $87,8 \%$ mereka masih melakukan aktivitas seperti biasanya saat mengalami dismenore dan $12,2 \%$ menggunakan obat pereda sakit untuk mengurangi sakit pada saat datang bulan (Handayani dkk, 2013).

Dari hasil studi pendahuluan yang dilakukan oleh peniliti siswi kelas $\mathrm{X}$ dan $\mathrm{XI}$ di SMA N 3 Nabire Kabupaten Nabire jumlah siswi yang saat ini mengemban pendidikan di SMAN 3 Nabire sebanyak 322 siswi. Berdasarkan survey pendahuluan dengan 10 siswi didapatkan 8 orang( $80 \%)$ diantaranya mengalami dysmenorhoe dan 2 orang ( $2 \%$ ) diantaranya tidak mengalami dysmenorhoe. Dari 8 orang tersebut mengaku sering ijin tidak masuk sekolah dikarenakan dysmenorhoe.

\section{METODE PENELITIAN}

Jenis penelitian ini menggunakan teknik penelitian dengan motede survey analitik dengan pendekatan cross sectional. Populasi dalam penelitian ini Pengumpulan data telah dilaksanakan pada tanggal 14 september - 20 Oktober 2020 melalui Daring, dengan cara membagikan Quesioner melalui Link atau google form yang telah dibuat oleh peneliti kepada siswi SMA Negeri 3 Nabire. Populasi pada penelitian adalah seluruh siswi Kelas X, XI dan XII pada bulan Juli tahun 2020 di SMA Negeri 3 Nabire Kabupaten Nabire sebanyak 322 siswi. Teknik pengambilan sample dengan Purposive Sampling dengan jumlah sampel sebanyak 121 siswa. 


\section{HASIL PENELITIAN}

\section{a. Analisis Univariat}

1) Usia

\section{Grafik 1}

Usia Siswi Yang Bersekolah Di SMA Negeri 3 NabireTahun 2020

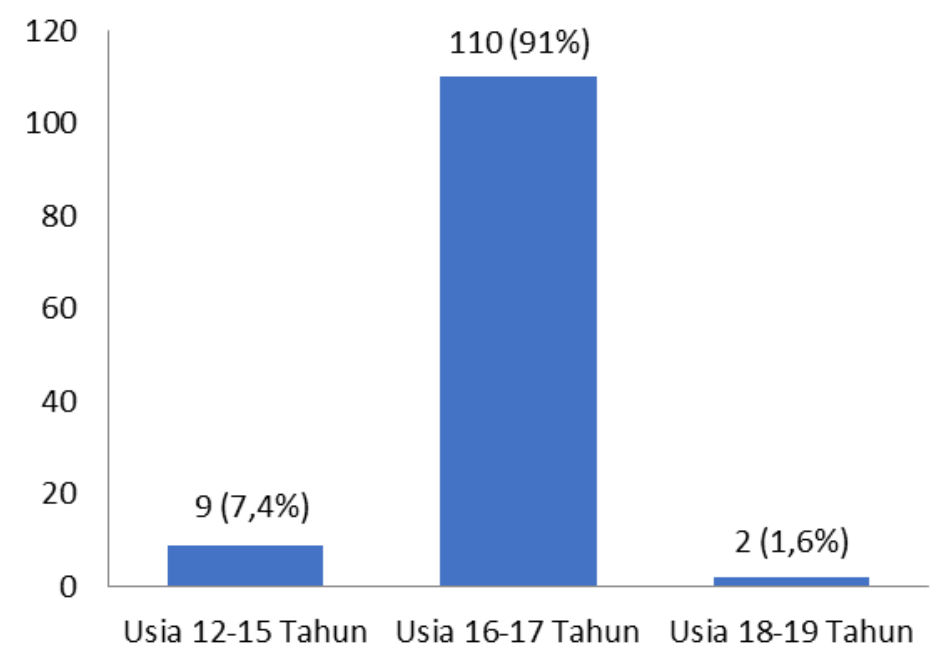

Sumber : Data Primer SMA Negeri 3 Nabire

Berdasarkan grafik 4.1. dapat diketahui bahwa usia dari 121 siswi yang bersekolah di SMA Negeri 3, dimana batasan usia remaja menurut Hurlock dibagi menjadi 3 fase, yaitu Remaja Awal sebanyak 9 (7.4\%) siswi, Remaja Madya 110 (91\%) siswi dan Remaja Akhir sebanyak 2 $(1.6 \%)$ siswi. Pada tabel diatas dapat dilihat bahwa batasan usia yang paling dominan pada siswi di SMA Negeri 3 Nabire adalah batasan usia remaja madya, yaitu $91 \%$.

2) Menarche

Grafik 4.2 Usia Siswi Saat Mengalami Haid Pertama Kali (Menarche) Di SMA Negeri 3 Nabire

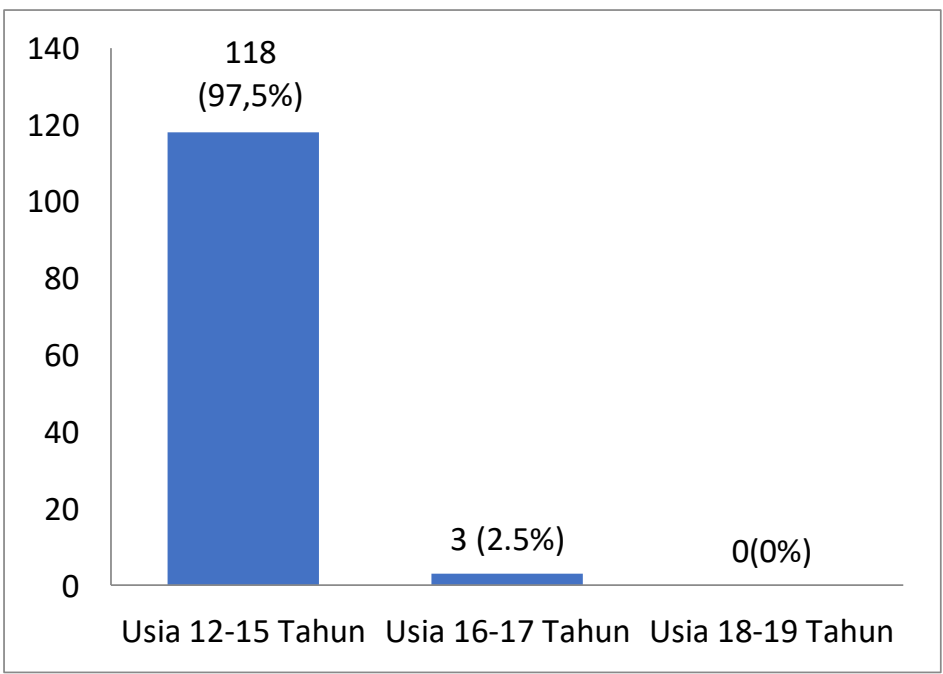

(Sumber : Data Primer SMA Negeri 3 Nabire, 2020)

Berdasarkan grafik 2. dapat diketahui bahwa usia siswi yang haid pertama kali dari 121 siswi yang bersekolah di SMA Negeri 3, dimana batasan usia remaja 
menurut Hurlock dibagi menjadi 3 fase, yaitu remaja awal sebanyak 118 $(97.5 \%)$ siswi, remaja madya $3(2.5 \%)$ dan . Pada tabel diatas dapat dilihat bahwa batasan usia yang paling dominan pada siswi di SMA Negeri 3 Nabire adalah batasan usia remaja awal, yaitu $97.5 \%$.

\section{3) Suku}

Grafik 3 Suku Siswi Di SMA Negeri 3 Nabire Tahun 2020

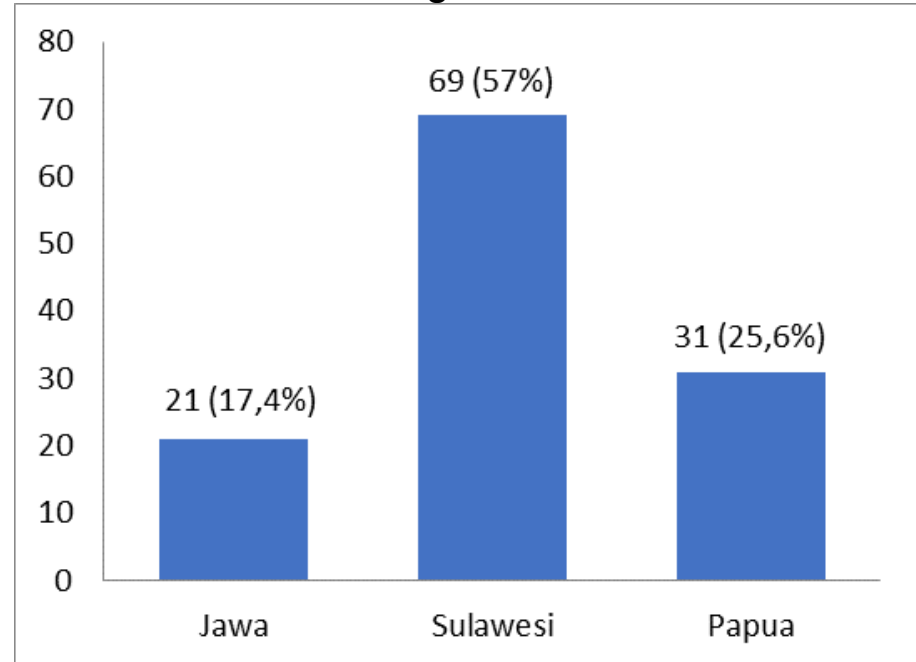

(Sumber : Data Primer SMA Negeri 3 Nabire, 2020)

Berdasarkan grafik 3 dapat diketahui bahwa suku siswi dari 121 siswi yang bersekolah di SMA Negeri 3, dimana suku tersebut dibagi 3 wilayah daerah besar, yaitu Wilayah daerah Jawa sebanyak 21 (17.4\%), wilayah daerah Sulawesi 69 (57\%), dan wilayah daerah Papua 31 (25.6\%). Pada tabel diatas dapat dilihat bahwa suku yang paling dominan pada siswi di SMA Negeri 3 Nabire adalah dari wilayah daerah Sulawesi, yaitu 57\%.

\section{4) Siswi yang mengalami Dysmenorohoe}

\section{Grafik 4}

Data Siswi Yang Mengalami Dysmenorea Di SMA Negeri 3 Nabire Tahun 2020

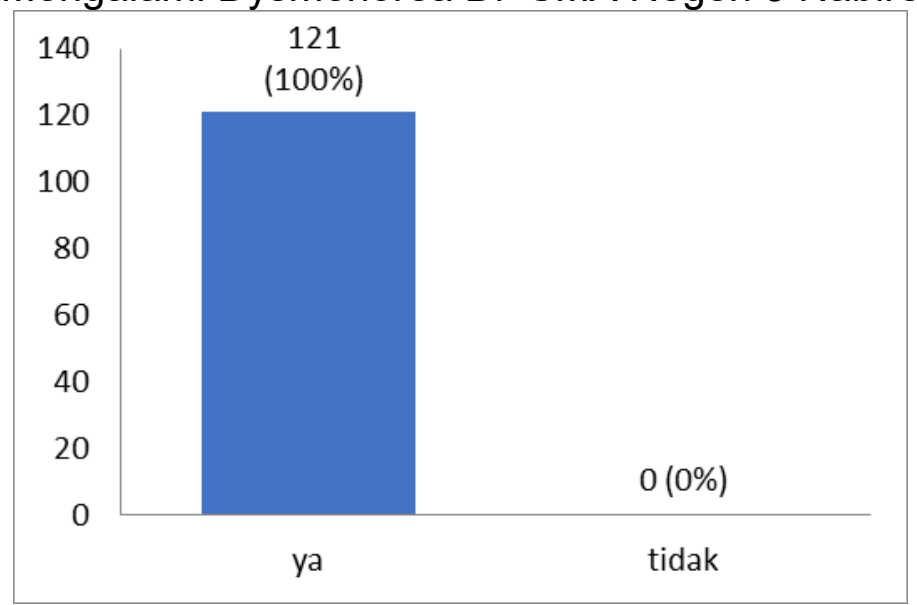

(Sumber: Data Primer SMA Negeri 3 Nabire) 


\section{5) Tingkat Nyeri Haid}

\section{Grafik 5}

Tingkatan Nyeri Haid ( Dysmenorea) Pada Siswi Di SMA Negeri 3 Nabire Tahun 2020

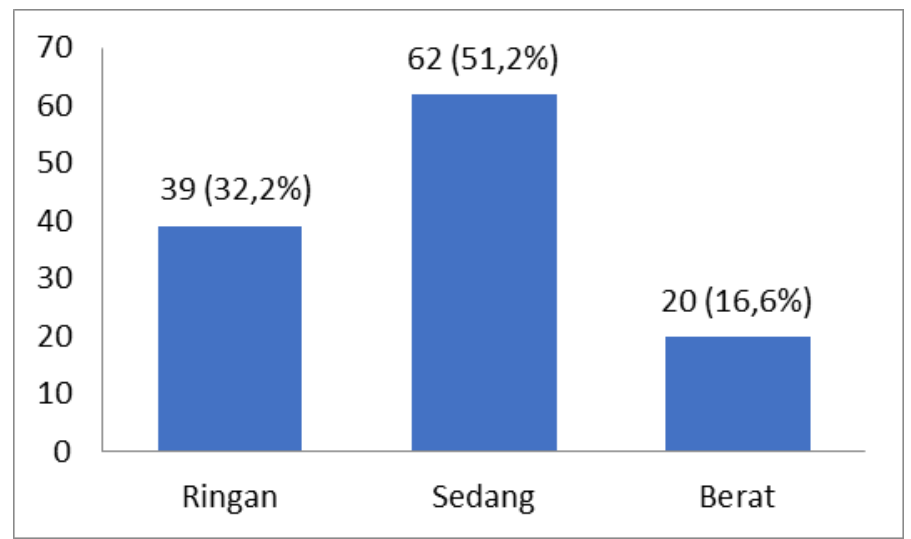

(Sumber : SMA Negeri 3 Nabire,2020)

Berdasarkan grafik 4.5. dapat diketahui bahwa dari 121 siswi yang bersekolah di SMA Negeri 3 yang mengalami nyeri haid, memiliki tingkat nyeri yang berbeda-beda, yaitu siswi yang yang mengalami nyeri haid tingkat ringan sebanyak $39(32.2 \%)$, siswi yang mengalami nyeri haid tingkat sedang sebanyak $62(51.2 \%)$, dan siswi yang mengalami nyeri haid tingkat berat sebanyak 20 (16.6\%). Berdasarkan data diatas tingkat nyeri haid sedang cukup tinggi jika dilihat dengan jumlah responden sebanyak 121 siswi.

\section{6) Kehadiran Siswi}

\section{Grafik 7}

Hasil Wawancara Wali Kelas XI dan XII tentang Aktivitas Siswi ljin Tidak Masuk Karena Nyeri Haid Di SMA Negeri 3 Nabire Tahun 2020

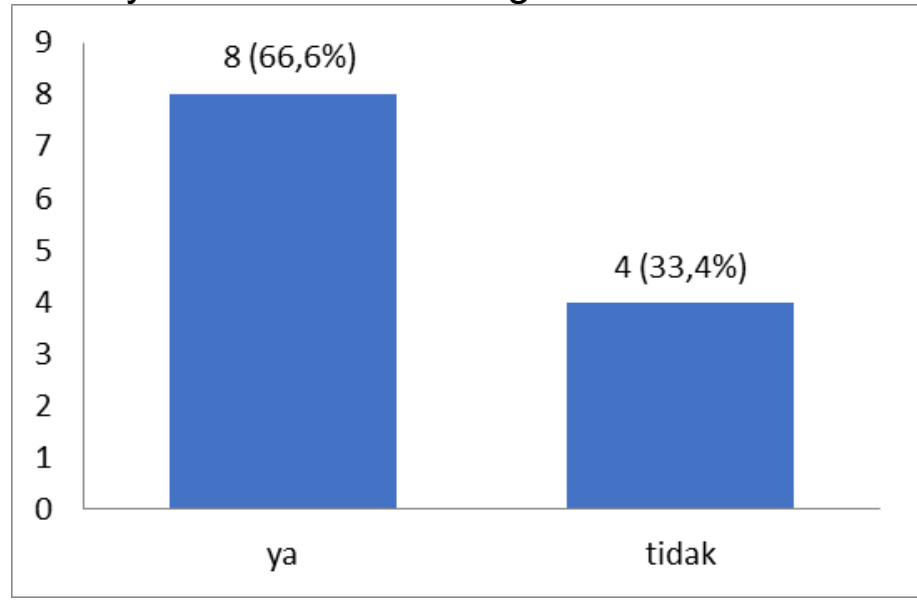

(Sumber : SMA Negeri 3 Nabire)

Berdasarkan Grafik 7 dapat diketahui bahwa dari 12 siswa yang terdata oleh guru diketahui ijin tidak mengikuti pelajaran dikarenakan dysmenorhoe diketahui 
8 siswa $(66,66 \%)$ diantaranya memilih tidak masuk dengan ijin alasan sakit, dan $4(33,4 \%)$ diantaranya sudah berusaha masuk namun ijin pulang dikarenakan dysmenorhoe.

7) Pengetahuan tentang dymenorhoe

Tabel 1 Distribusi Frekuensi Pengetahuan tentang dysmenorhoe pada siswi SMA Negeri 3 Nabire

\begin{tabular}{lcc}
\hline $\begin{array}{l}\text { Pengetahuan tentang } \\
\text { dysmenorhoe }\end{array}$ & Frekuensi & Persentase \\
\hline Baik & 1 & $0,8 \%$ \\
Cukup & 27 & $22,3 \%$ \\
Kurang & 93 & $76,85 \%$ \\
\hline Total & 121 & $100 \%$ \\
\hline
\end{tabular}

Berdasarkan tabel 1 diatas dapat disimpulkan bahwa sebagian besar siswi SMA Negeri 3 Nabire berpengetahuan Kurang tentang dysmenorhoe yaitu sebanyak 93 orang $(76,85 \%)$.

8) Aktifitas Belajar

Tabel 2 Distribusi Frekuensi aktivitas belajar pada siswi SMA Negeri 3 Nabire

\begin{tabular}{lcc}
\hline \multicolumn{1}{c}{ Aktifitas Belajar } & Frekuensi & Persentase \\
\hline Tidak terganggu & 39 & $32,23 \%$ \\
Terganggu & 79 & $65,28 \%$ \\
Sangat terganggu & 3 & $2,47 \%$ \\
\hline Total & 121 & $100 \%$ \\
\hline
\end{tabular}

Berdasarkan tabel 2 diatas dapat disimpulkan bahwa sebagian besar siswi SMA Negeri 3 Nabire terganggu aktifitas belajarnya yaitu sebanyak $79(65,28 \%)$.

b. Analisis Bivariat

Pengaruh Pengetahuan tentang Dysmenorhoe Terhadap Aktifitas Belajar di SMAN 3 Nabire

Tabel 3

Hasil Uji Bivariat Dengan Uji Kendall Tau

\begin{tabular}{ccccccc}
\hline $\begin{array}{c}\text { Pengetahuan } \\
\text { Tentang } \\
\text { Disminorea }\end{array}$ & $\begin{array}{c}\text { Tidak } \\
\text { terganggu }\end{array}$ & Terganggu & $\begin{array}{c}\text { Total } \\
\text { Sangat } \\
\text { Terganggu }\end{array}$ & $\begin{array}{c}\text { Koefisien } \\
\text { value }\end{array}$ & & \\
\hline Korelasi \\
Cukup & 35 & 56 & 2 & 93 & 0,042 & $-0,183$ \\
Baik & 4 & 22 & 1 & 27 & & \\
Total & 0 & 1 & 0 & 1 & & \\
\hline
\end{tabular}

Berdasarkan data tabel 3 diatas dengan menggunakan uji kendall tau diketahui nilai Sig. (2-tailed) adalah sebesar 0,042 <0,05, maka HO ditolak dan Ha diterima. Sehingga dapat disimpulkan bahwa ada pengaruh antara pengetahuan tentang dysmenorhoe terhadap aktivitas belajar mahasiswa. 
Berdasarkan tabel output diatas, diketahui koefisien korelasi (Correlation Coefficient) antara variabel pengetahuan dan aktifitas belajar bernilai negatif yakni sebesar 0,183 . Maka dapat disimpulkan ada hubungan yang "negatif" antara variabel pengetahuan dengan aktifitas belajar. Hubungan negatif atau tidak searah bermakna jika makin tinggi pengetahuan siswi tentang disminore maka semakin rendah jumlah siswa yang mengalami gangguang aktivitas belajar. Sebaliknya jika makin rendah pengetahuan siswi tentang disminorea maka akan meningkat jumlah siswi yang mengalami gangguan aktifitas belajar.

\section{PEMBAHASAN}

\section{1) Pengaruh Pengetahuan tentang Dysmenorhoe Terhadap Aktifitas Belajar di SMAN 3 Nabire}

Berdasarkan output uji korelasi kendall's tau-b diketahui nilai signifikan atau Sig. (2-tailed) antara variabel Pengetahuan Siswi tentang disminore dengan Aktivitas Belajar adalah sebesar $0,042<0,05$, maka dapat disimpulkan bahwa ada hubungan yang signifikan (nyata) antara variabel Pengetahuan Siswi tentang disminore dengan aktifitas belajar.

Berdasarkan tabel output uji korelasi kendall's tau-b diatas, diketahui nilai koefisien korelasi (Correlation Coefficient) antara variabel pengetahuan dengan aktivitas belajar adalah sebesar 0,183. Dengan demikian, maka dapat disimpulkan bahwa hubungan antara variabel pengetahuan dan aktifitas belajar adalah "sangat lemah".

Berdasarkan tabel output diatas, diketahui koefisien korelasi (Correlation Coefficient) antara variabel pengetahuan dan aktifitas belajar bernilai negatif yakni sebesar 0,183. Maka dapat disimpulkan ada hubungan yang "negatif" antara variabel pengetahuan dengan aktifitas belajar. Hubungan negatif atau tidak searah bermakna jika makin tinggi pengetahuan siswi tentang disminore maka semakin rendah jumlah siswa yang mengalami gangguan aktivitas belajar. Sebaliknya jika makin rendah pengetahuan siswi tentang disminorea maka akan meningkat jumlah siswi yang mengalami gangguan aktifitas belajar.

Hal ini didukung oleh penelitian Sabaruddin dan Arifah (2017) yang meneliti hubungan antara pengetahuan tentang dysmenorhoe dengan perilaku penanganan dysmenorhoe dimana didapatkan hasil dengan uji Kendall-tau didapatkan $p$-value 0,035 artinya ada hubungan pengetahuan tentang dysmenorhea dengan perilaku penanganan dysmenorhea, dengan koefisien korelasi kendall's-tau 0,280 artinya semakin baik tingkat pengetahuan tentang dysmenorhea, semakin baik pula perilaku penanganan dysmenorhea yang dilakukan. Jika Perilaku penanganan dysmenorhoe semakin baik, maka gangguan aktivitas belajar akan semakin berkurang. Hal ini sejalan dengan penelitian ini dimana koefisien korelasi -0,183 dimana jika makin rendah pengetahuan siswa tentang dysmenorhoe maka akan semakin meningkat jumalh siswa yang mengalami gangguan aktivitas belajar. Menurut peneliti, gangguan aktivitas belajar ini meningkat pada responden dengan pengetahuan rendah dikarenakan mereka tidak mengetahui penanganan yang baik tentang dysmenorhoe sehingga menyebabkan memilih untuk membolos sekolah dan meninggalkan pelajaran di kelas sehingga muncul gangguan 
aktivitas belajar. Hal ini didukung oleh penelitian Anggi (2021) yang menyebutkan ada hubungan yang bermakna antara dismenore dengan aktivitas belajar $p<0,0006$ penelitian tersebut menyebutkan jika seorang siswi mengalami dismenorea maka aktivitas belajar di sekolah menjadi terganggu karena kesulitan berkonsentrasi belajar pada saat proses belajar mengajar dan motivasi belajar akan menurun dan tidak jarang hal ini membuat mereka memilih tidak masuk ke sekolah.

Hal ini tidak sejalan dengan penelitian Dewi $R$ (2019) yang menyebutkan bahwa tidak ada hubungan antara pengetahuan tentang dysmenorhoe dengan sikap dalam penanganan dysmenorhoe di SMA Assandiyah Palembang tahun 2016 dengan $p$ value 1,000 $(>, 0,05)$.

\section{SIMPULAN DAN SARAN}

\section{SIMPULAN}

Sebanyak 93 Siswi $(76,9 \%)$ memiliki tingkat pengetahuan kurang, sebanyak 27 siswi $(22,3 \%)$ memiliki tingkat pengetahuan cukup dan sebanyak 1 siswi $(0,8 \%)$ memiliki tingkat pengetahuan baik. 39 siswi $(32,2 \%)$ tidak mengalami gangguan aktivitas belajar, sebanyak 82 siswi $(67,8 \%)$ terganggu aktifitas belajarnya dan sebanyak 3 siswi $(2,5 \%)$ sangat terganggu aktifitas belajarnya. Ada pengaruh pengetahuan tentang disminore terhadap aktifitas belajar Siswi SMA Negeri 3 Nabire $p<0,05$ ( $p=$ 0,042 ) dengan nilai Correlation Coefficient $-0,183$ (sangat lemah) yang artinya juga makin tinggi pengetahuan siswi tentang disminore maka semakin rendah jumlah siswa yang mengalami gangguan aktivitas belajar

\section{SARAN}

Diharapkan kepada pihak sekolah bekerja sama dengan tenaga kesehatan wilayah setempat misalnya Puskesmas untuk bisa menambah pengetahuan siswi tentang dysmenorhea.

\section{DAFTAR PUSTAKA}

Anggi,Saputra, Khasanah, U., Hayati, S., Maidartati, \& Susilawati, S. (2021). Hubungan Disminore dengan Aktivitas Belajar pada Remaja Siswi Kelas X dan XI SMA N Rancakalong. Jurnal Keperawatan BSI, 9(2), 246-252. Retrieved from http://ejurnal.ars.ac.id/index.php/keperawatan/article/view/627

Anurogo, Ditto. (2011). Nyeri Haid. Yogyakarta: Penerbit Andi.

Atkinson, R.C. (2005) Pengantar Psikologi (terjemahan Taufiq dan Barhana). Jakarta : Erlangga.

Dewi, R. (2019). Hubungan Pengetahuan Terhadap Sikap Remaja Putri Dalam Penanganan Dismenore Di Sma Assanadiyah Palembang Tahun 2016: Relationship between Knowledge and Attitudes of Young Women in Handling Dysmenorrhea in Palembang Senior High School in 2016. Journal of Midwifery and Nursing, 1(1), 19-23. Retrieved from http://iocscience.org/ejournal/index.php/JMN/article/view/15 
Fatmawati, M., Riyanti, E., \& Widjanarko, B. (2016). Perilaku Remaja Puteri Dalam Mengatasi Dismenore (Studi Kasus pada Siswi SMK Negeri 11 Semarang). Jurnal Kesehatan Masyarakat (Undip), 4(3), 1036-1042.

Gulzar, S., Khan, S., Abbas, K., Arif, S., Husain, S. S., Imran, H., \& Sommer, J. (2015). Prevalence, perceptions and effects of dysmenorrhea in school going female adolescents of Karachi, Pakistan. International Journal of Innovative Research and Development, 4(2), 235-40.

Handayani., Gamayanti, I.L., Julia, M. (2013).Dismenore dan kecemasan pada remaja. Sari Pediatri, Vol.15 No.1, h.2.

Kumalasari, I \& Andhyantoro, I. (2012). Kesehatan Reproduksi Untuk Mahasiswa Kebidanan Dan Keperawatan. Jakarta: Salemba Medika.

Mansjoer, A. (2003). Kapita Selekta Kedokteran. Media Aesculpius : Jakarta

Murtiningsih, M. (2015). Penurunan Nyeri Dismenore Primer Melalui Kompres Hangat Pada Remaja. Jurnal online diakses pada (15-09-2018)

Purwanto. (2003). Ilmu Pendidikan Teoritis dan Praktis. Bandung: Remaja Rosdakarya

Ngu, S.F., Chia, C., Lai, J. H., Kwong, P., Lau, F. P., Leung, K., Wong, F. C. (2013). Dysmenorrhoea among Hong Kong universitystudents:prevalence,impact, and management.Hong KOng Medical,volume19, no. 3, Juni 2013:222228.Diterima darihttps://hkmj.orgpada tanggal30 Maret 2017

Sabaruddin, H. F., Arifah, S., \& Fitriahadi, E. (2017). Hubungan Pengetahuan Tentang Dysmenorhea Dengan Perilaku Penanganan Dysmenorhea Di Pesantren As-Syalafiah Mlangi Yogyakarta.

Sari, W., Indrawati, L.\& Harjanto, B.D. (2012). Panduan lengkap kesehatan wanita. Jakarta: Penebar Swadaya Grup

WHO. (2014). Health For World's Adolescent. Geneva: WHO. https://apps.who.int/adolescent/seconddecade/files/1612_MNCAH_HWA_Exe cutive_Summary.pdf 